\title{
Qualidade higiênico-sanitária de alimentos comercializados em food trucks em Belo
}

\section{Horizonte, Brasil}

\author{
Hygienic-sanitary quality of food sold in food trucks in Belo Horizonte, Brazil \\ Calidad higiénico-sanitaria de los alimentos vendidos en food trucks en Belo Horizonte, Brasil
}

Recebido: 08/09/2021 | Revisado: 15/09/2021 | Aceito: 16/09/2021 | Publicado: 18/09/2021

\author{
Drisana de Azevedo Nunes \\ ORCID: https://orcid.org/0000-0002-5378-8677 \\ Centro Universitário UNA, Brasil \\ E-mail: dridxs.8@gmail.com \\ Maria Marta Amancio Amorim \\ ORCID: https://orcid.org/0000-0001-8268-2508 \\ CEMRI/Universidade Aberta de Lisboa, Portugal \\ E-mail: martamorim@hotmail.com \\ Fernanda Meneghello Delvivo \\ ORCID: https://orcid.org/0000-0002-7678-6121 \\ Centro Universitário UNA, Brasil \\ E-mail: fernandadelvivo@prof.una.br \\ Suélen Aparecida Freitas \\ ORCID: https://orcid.org/0000-0001-9960-3730 \\ Centro Universitário UNA, Brasil \\ E-mail: suelenapfreitas@gmail.com \\ Patrícia do Bom Sucesso Xavier \\ ORCID: https://orcid.org/0000-0003-2367-8941 \\ Centro Universitário UNA, Brasil \\ E-mail: patriciabsx@yahoo.com \\ Adriene Ribeiro Lima \\ ORCID: https://orcid.org/0000-0003-2653-066X \\ Universidade Federal Fluminense, Brasil \\ E-mail: adrienelima@id.uff.br
}

\begin{abstract}
Resumo
O objetivo deste estudo é avaliar a qualidade higiênico-sanitária de alimentos comercializados na região central de Belo Horizonte, Brasil. A venda de alimentos em vias públicas pode apresentar inúmeros problemas higiênicosanitários. Uma das ferramentas que podem auxiliar na verificação destes é a análise microbiológica, pois alguns microrganismos são indicadores de contaminação. Foram coletadas e aferidas as temperaturas de cinco amostras de cachorro-quente, cinco hambúrguer e cinco macarrão na chapa. Os microrganismos analisados foram coliformes à $45^{\circ} \mathrm{C}$, Staphylococcus aureus, Bacillus cereus e Salmonella spp. Dentre as 15 amostras coletadas, $83 \%$ apresentou-se em desacordo com a temperatura mínima de $60^{\circ} \mathrm{C}$, sendo cinco amostras de cachorro-quente, quatro de hambúrguer e três de macarrão na chapa, com temperaturas variando entre $30,6^{\circ} \mathrm{C}$ a $65^{\circ} \mathrm{C}$. Todas as amostras apresentaram resultados satisfatórios em relação à pesquisa de Salmonella spp. e contagem de Bacillus cereus. Apesar destas amostras estarem em conformidade com estes indicadores microbiológicos, as temperaturas verificadas no decorrer da compra apontaram um produto inadequado para consumo. Em relação às contagens de coliformes à $45^{\circ} \mathrm{C} \mathrm{e}$ Staphylococcus aureus, $13,3 \%$ e $40 \%$ das amostras, respectivamente, apresentaram-se fora dos padrões microbiológicos. Observa-se a necessidade de maior atenção na área de segurança dos alimentos em food trucks, portanto, sugere-se que o serviço de vigilância sanitária do município reforce a fiscalização e aplique periodicamente checklists para avaliar a qualidade higiênico-sanitária nestes locais.
\end{abstract}

Palavras-chave: Técnicas microbiológicas; Coliformes; Staphylococcus aureus; Higiene.

\section{Abstract}

This study aims to evaluate the hygienic sanitary quality of foods in the central region of Belo Horizonte, Brazil. The sale of food on public roads can present numerous hygienic and sanitary problems. One of the tools that can help to verify these is the microbiological analysis, as some microorganisms are indicators of contamination. The temperatures of five samples of hot dogs, five hamburguers and five pasta were collected and measured. The microorganisms analyzed were coliforms at $45^{\circ} \mathrm{C}$, Staphylococcus aureus, Bacillus cereus, and Salmonella spp. Among the 15 samples collected, $83 \%$ were in disagreement with the minimum temperature of $60^{\circ} \mathrm{C}$, with five samples of hot dogs, four of hamburger and three of pasta, with temperatures ranging from $30.6^{\circ} \mathrm{C}$ to $65^{\circ} \mathrm{C}$. All samples showed satisfactory results concerning to the investigation of Salmonella spp. and Bacillus cereus count. 
Despite these samples being following these microbiological indicators, the temperatures verified during the purchase indicated a product unsuitable for consumption. Regarding the counts of coliforms at $45^{\circ} \mathrm{C}$ and Staphylococcus aureus, $13.3 \%$ and $40 \%$ of the samples, respectively, were outside the microbiological standards. There is a need for greater attention in the area of food safety in food trucks, therefore, it is suggested that the city's sanitary surveillance service reinforce inspection and periodically apply checklists to assess the hygienic-sanitary quality in these places.

Keywords: Microbiological techniques; Coliforms; Staphylococcus aureus; Hygiene.

\section{Resumen}

El objetivo de este estudio es evaluar la calidad higiénica sanitaria de comidas en la región central de Belo Horizonte, Brasil. La venta de alimentos en la vía pública puede presentar numerosos problemas higiénicos y sanitarios. Una de las herramientas que puede ayudar a verificar estos es el análisis microbiológico, ya que algunos microorganismos son indicadores de contaminación. Se recogieron y midieron las temperaturas de cinco muestras de hot dogs, cinco hamburguer y cinco pasta. Los microorganismos analizados fueron coliformes a $45^{\circ} \mathrm{C}$, Staphylococcus aureus, Bacillus cereus y Salmonella spp. De las 15 muestras recogidas, el 83\% estaba en desacuerdo con la temperatura mínima de $60^{\circ} \mathrm{C}$, con cinco muestras de hot dogs, cuatro de hamburguer y tres de pasta, con temperaturas que oscilan entre $30,6^{\circ} \mathrm{C}$ y $65^{\circ} \mathrm{C}$ Todas las muestras arrojaron resultados satisfactorios en relación con la investigación de Salmonella spp. y recuento de Bacillus cereus. A pesar de que estas muestras están de acuerdo con estos indicadores microbiológicos, las temperaturas verificadas durante la compra indicaron un producto no apto para el consumo. En cuanto a los recuentos de coliformes a $45^{\circ} \mathrm{C}$ y Staphylococcus aureus, el 13,3\% y el $40 \%$ de las muestras, respectivamente, se encontraban fuera de los estándares microbiológicos. Existe la necesidad de una mayor atención en el área de seguridad alimentaria en los camiones de comida, por lo que se sugiere que el servicio de vigilancia sanitaria de la ciudad refuerce la inspección y aplique periódicamente listas de verificación para evaluar la calidad higiénico-sanitaria en estos lugares.

Palabras clave: Técnicas microbiológicas; Coliformes; Staphylococcus aureus; Higiene.

\section{Introdução}

Cerca de 33,9\% dos gastos destinados à alimentação dos brasileiros são utilizados com alimentos fora do domicílio, segundo dados da Pesquisa de Orçamentos Familiares (POF) de 2017-2018 (IBGE, 2019), devido principalmente à praticidade e o baixo custo (Stein et al., 2017).

Dentre os alimentos fora do domicílio se destacam as comidas de rua, definidas como "o conjunto de alimentos e bebidas preparados ou vendidos por ambulantes, especialmente nas ruas e/ou lugares públicos” (Pertilé, 2013, p. 301). Esses produtos estão cada vez mais comuns, principalmente nas regiões centrais das cidades e como consequência dessa expansão, surge uma nova tendência, originada nos Estados Unidos, o food truck. Este tipo de negócio caracteriza-se por ser uma cozinha móvel, adaptada em veículos como caminhonetes, trailers, furgões e vans que funcionam pequenas lanchonetes e restaurantes (Costa, 2017; Loriato \& Pelissari, 2017).

Em Belo Horizonte, local da realização dessa pesquisa, os food trucks devem possuir a licença válida de funcionamento do veículo e comércio de alimentos em locais públicos, expedida pelo município. A Prefeitura Municipal liberou vagas de estacionamento do sistema de rotativo digital para serem utilizadas por food trucks que exercem atividades de comercialização de alimentos em locais públicos, segundo a portaria BHTrans DSV número 006/2020 (Belo Horizonte, 2020). Essa medida propicia o aumento dos food trucks na cidade de Belo Horizonte, conhecida como a capital dos bares.

$\mathrm{O}$ comércio de comidas de rua nos food trucks requer cuidados redobrados quanto à qualidade higiênico-sanitária. Geralmente falhas no controle de temperaturas permite que muitos alimentos fiquem expostos às temperaturas de risco, o que favorece o rápido crescimento de microrganismos patogênicos e o desenvolvimento das doenças transmitidas por alimentos (DTA) (Lemunie \& Weber, 2018; Cunha et al., 2017; Stein et al. 2017).

As DTA têm sua origem na ingestão de preparações com presença de patógenos e/ou toxinas por eles produzidas, o que provoca intoxicações e infecções nos comensais, e é uma das questões de saúde pública mais debatidas na atualidade (Stein et al., 2017). No Brasil, entre 2000 e 2017 ocorreram 12.660 surtos de DTA, grande parte na região sudeste, ocasionando 2.372.132 expostos, 239.164 doentes e 186 óbitos. Cerca de 11,77\% dos casos de DTA são causados por esses 
alimentos mistos, tendo como principais agentes etiológicos a Salmonella spp. (35\%), Escherichia coli (28,2\%), e Staphylococcus aureus (18,2\%) (Brasil, 2018).

Como os food trucks de Belo Horizonte comercializam alimentos mistos é importante avaliar a qualidade higiênicosanitária desses produtos. A análise microbiológica é uma importante ferramenta para verificar se o alimento está adequado para o consumo. Alguns microrganismos são indicadores de contaminação como, as bactérias do grupo dos coliformes termotolerantes (coliformes a $45^{\circ} \mathrm{C}$ ), Escherichia coli e Staphylococcus aureus. Altas contagens destas bactérias nas preparações indicam conservação e armazenamento sob más condições sanitárias e falhas higiênicas dos manipuladores (Mendonça et al., 2020).

Diante desse contexto, esse estudo tem por objetivo avaliar a qualidade higiênico-sanitária de alimentos comercializados em food trucks na região central de Belo Horizonte, Brasil.

\section{Metodologia}

Esse estudo se caracteriza por ser quantitativo ao coletar dados numéricos por meio do uso de medições de grandezas obtendo-se por meio da metrologia, números com suas respectivas unidades (Pereira el al., 2018), como os valores das temperaturas e das contagens de microrganismos de comidas de rua em cinco food trucks localizados na região central de Belo Horizonte.

Amostras de três comidas de rua dentre elas, cinco cachorro-quente, cinco hambúrgueres e cinco macarrão na chapa foram compradas nesses cinco estabelecimentos, no ano de 2018. O cachorro-quente, na sua versão básica foi composto de pão de leite, salsicha, molho de tomate, milho verde e batata palha. Quanto ao tipo de hambúrguer padronizou-se coletar o sanduiche x-tudo, contendo pão de hambúrguer, hambúrguer, queijo, presunto, bacon, ovo, tomate e alface. O macarrão na chapa era composto de macarrão, filé de frango, carne bovina, carne suína, bacon, queijo, pimentão, milho verde, tomate, molho inglês e/ou shoyo.

A temperatura das comidas de rua foi aferida após os sanduíches e o macarrão serem montados nas embalagens comercializadas. Utilizou-se um termômetro espeto, com temperatura variando entre $-50^{\circ} \mathrm{C} /+300^{\circ} \mathrm{C}$ e a sua adequação foi verificada de acordo com os parâmetros da RDC 216 de 2004, sendo iguais ou superiores a $60^{\circ} \mathrm{C}$ (Brasil, 2004).

Logo após a aferição da temperatura, as amostras foram acondicionadas em caixa térmica com gelo reciclável e transportadas ao Laboratório de Microbiologia de Alimentos do Centro Universitário Una, Belo Horizonte, com tempo máximo de 30 minutos.

Os microrganismos analisados foram coliformes à $45^{\circ} \mathrm{C}$, em que o resultado é expresso em "Número Mais Provável" por grama da amostra (NMP/g), Staphylococcus aureus e Bacillus cereus, sendo os resultados expressos em Unidades Formadoras de Colônias por grama de amostra (UFC/g) e deteç̧ão de Salmonella spp em 25 gramas de amostra. A metodologia utilizada para análise seguiu o Compendium of Methods for the Microbiological Examination of Food da American Public Health Association (APHA). Pesou-se 25g de cada amostra diluída em $225 \mathrm{~mL}$ de água peptonada a 0,1\%, obtendo-se a diluição $10^{-1}$. Posteriormente, pipetou-se $1 \mathrm{~mL}$ da diluição $10^{-1}$ em $9 \mathrm{~mL}$ de água peptonada a $0,1 \%$, obtendo-se a diluição $10^{-2}$. E assim sucessivamente, até a diluição $10^{-3}$. Todas as análises foram realizadas em triplicata (APHA, 2015).

A contagem de coliformes à $45^{\circ} \mathrm{C}$ foi realizada pelo método dos tubos múltiplos. Alíquotas de $1 \mathrm{~mL}$ de cada diluição foram inoculadas em séries de três tubos, contendo $9 \mathrm{~mL}$ de caldo Lauril Sulfato Triptose (LST), com tubo de Duhran invertido. Os tubos foram incubados a $37^{\circ} \mathrm{C}$ por 24 horas. Uma alçada de cada tubo positivo, que apresentaram turvação e formação de gás visível no tubo de Durhan foi transferida para tubos contendo caldo Escherichia coli (EC), que foram incubados a $45^{\circ} \mathrm{C}$ por 24 horas (APHA, 2015). 
Para a detecção de Salmonella spp. foi realizado o processo de pré-enriquecimento da amostra, adicionando-se $25 \mathrm{~g}$ desta em $225 \mathrm{~mL}$ de água peptonada. A amostra foi homogeneizada e incubada a $37^{\circ} \mathrm{C}$ por 24 horas. A partir do préenriquecimento, foram inoculados $1 \mathrm{~mL}$ de cada diluição para tubos contendo $10 \mathrm{~mL}$ de caldo Tetrationato (TT) e caldo Rappaport Vassiliansis (RV), em seguida os tubos foram incubados a $35^{\circ} \mathrm{C}$ por 24 horas. A partir dos caldos seletivos de enriquecimento, foram inoculadas uma alçada de cada tubo em placas de ágar Xilose Lisina- Desoxicolato (XLD) e ágar Hektoen (HE). As placas foram incubadas invertidas a $37^{\circ} \mathrm{C}$ por 48 horas. Colônias típicas foram inoculadas em tubos contendo ágar Tríplice Açúcar Ferro (TSI). Os tubos foram incubados a $37^{\circ} \mathrm{C}$ por 24 horas. Foram considerados positivos os tubos em que houveram viragem do indicador vermelho de fenol para vermelho com produção de gás. Após, com auxílio de uma agulha de platina foi inoculado a partir de tubos positivos em TSI em tubos com o meio SIM. Nos tubos que apresentaram crescimento difuso (enegrecimento do meio, motilidade positiva) e após adição de 3 gotas de reativo de Kovacs, houve reação negativa para indol (APHA, 2015).

A análise de Staphylococcus aureus foi realizada com a inoculação de $0,1 \mathrm{~mL}$ de cada diluição em ágar Baird Parker realizando-se diluições de $10^{-1}$ a $10^{-3}$, utilizando o método de espalhamento em superfície. Em seguida, as placas foram incubadas invertidas a $37^{\circ} \mathrm{C}$ por 48 horas. Foram consideradas as colônias negras com bordas regulares, apresentando halo de hidrólise. Para a confirmação de Staphylococcus aureus foram selecionadas cinco colônias típicas e atípicas de cada placa para o teste da coagulase, que consiste na comprovação da capacidade de coagular o plasma pela ação da enzima coagulase (APHA, 2015).

Para enumeração de Bacillus cereus usou-se a contagem em placas, $0,1 \mathrm{~mL}$ das diluições seriadas $10^{-1}, 10^{-2}, 10^{-3}$ foram plaqueadas em meio seletivo Mannitol-Egg Yolk-Polymyxin agar (MYP) e espalhado com alça de Drigalski e incubado por $24 \mathrm{~h}$ a $37^{\circ} \mathrm{C}$. As colônias típicas de B. cereus apresentam cor rósea. Nas placas em que houveram crescimento isolou-se colônias em Ágar Sangue de carneiro, a fim de se verificar o processo de B-hemólise rodeadas por um halo de precipitação de lecitinase (APHA, 2015).

Os resultados obtidos em 2018 foram comparados aos valores preconizados pela RDC número 12 de 2001, resolução vigente naquele ano, que foi revogada pela RDC número 331 de 23/12/2019, a qual entrou em vigor em 23/12/2020 (Brasil, 2001; Brasil, 2019).

\section{Resultados}

Dentre as 15 amostras coletadas, $83 \%$ apresentaram temperatura em desacordo com a exigência de no mínimo $60{ }^{\circ} \mathrm{C}$ (Brasil, 2004), sendo cinco amostras de cachorro-quente, quatro de hambúrguer e três de macarrão na chapa, com temperaturas variando entre $30,6^{\circ} \mathrm{C}$ a $65^{\circ} \mathrm{C}$ (Tabela 1 ). 
Tabela 1. Temperatura das amostras de cachorro quente, hambúrguer e macarrão na chapa coletadas em food trucks na região central de Belo Horizonte, Brasil, 2018.

\begin{tabular}{|c|c|c|c|}
\hline Alimentos & Amostras & Local & Temperatura $\left({ }^{\circ} \mathbf{C}\right)$ \\
\hline \multirow{5}{*}{ Cachorro-quente } & 1 & $\mathrm{~A}$ & 44,7 \\
\hline & 2 & B & 45,8 \\
\hline & 3 & $\mathrm{C}$ & 31,6 \\
\hline & 4 & $\mathrm{D}$ & 48,4 \\
\hline & 5 & E & 36,7 \\
\hline \multirow{5}{*}{ Hambúrguer } & 6 & A & 65,0 \\
\hline & 7 & B & 30,6 \\
\hline & 8 & $\mathrm{C}$ & 34,6 \\
\hline & 9 & $\mathrm{D}$ & 32,3 \\
\hline & 10 & E & 40,4 \\
\hline \multirow{5}{*}{ Macarrão na chapa } & 11 & A & 62,3 \\
\hline & 12 & B & 57,6 \\
\hline & 13 & $\mathrm{C}$ & 45,1 \\
\hline & 14 & $\mathrm{D}$ & 78,9 \\
\hline & 15 & E & 58,9 \\
\hline
\end{tabular}

Fonte: Os autores (2021).

O cachorro-quente apresentou contagem elevada de coliformes a $45{ }^{\circ} \mathrm{C}$ nos locais D e E e de Staphylococcus aureus em B e C. Foram encontradas altas contagens de Staphylococcus aureus no hambúrguer comercializado pelos locais B e D e no macarrão na chapa vendido nos locais B e C. Assim, nota-se que o local B apresentou contagens elevadas de microrganismos indicadores nos três tipos de alimentos analisados, o local C e D em dois e o local E apenas em um tipo. O local A destacou-se por apresentar resultados das análises microbiológicas (Tabela 2) e temperaturas das amostras (Tabela 1) dentro dos padrões legais. 
Tabela 2. Análise microbiológica das amostras de cachorro quente, hambúrguer e macarrão na chapa coletadas em food trucks na região central de Belo Horizonte, Brasil, 2018.

\begin{tabular}{|c|c|c|c|c|c|c|}
\hline Amostra & Número & $\begin{array}{l}\text { Local } \\
\text { coleta }\end{array}$ & $\begin{array}{l}\text { Coliformes } \\
45^{\circ} \mathrm{C} \\
\left(\mathrm{NPM} / \mathbf{g}^{*}\right)\end{array}$ & $\begin{array}{c}\text { Staphylococcus } \\
\text { aureus } \\
\text { (UFC/g**) }\end{array}$ & $\begin{array}{l}\text { Bacillus cereus } \\
\text { (UFC/g**) }\end{array}$ & $\begin{array}{l}\text { Samonella } \\
\text { spp. }\end{array}$ \\
\hline \multirow{6}{*}{ Cachorro-quente } & 1 & $\mathrm{~A}$ & $<3,0$ & $<1,0 \times 10^{2}$ & $<1,0 \times 10^{2}$ & Ausente \\
\hline & 2 & B & $<3,0$ & $3,1 \times 10^{3}$ & $<1,0 \times 10^{2}$ & Ausente \\
\hline & 3 & $\mathrm{C}$ & $<3,0$ & $4,5 \times 10^{3}$ & $<1,0 \times 10^{2}$ & Ausente \\
\hline & 4 & $\mathrm{D}$ & $4,0 \times 10$ & $1,0 \times 10^{3}$ & $3,0 \times 10^{2}$ & Ausente \\
\hline & 5 & E & $2,3 \times 10$ & $5,0 \times 10^{2}$ & $<1,0 \times 10^{2}$ & Ausente \\
\hline & \multicolumn{2}{|c|}{ Padrão Legal*** } & $2,0 \times 10$ & $1,0 \times 10^{3}$ & $1,0 \times 10^{3}$ & Ausente \\
\hline \multirow{6}{*}{ Hambúrguer } & 6 & A & 4,0 & $2,0 \times 10^{2}$ & $<1,0 \times 10^{2}$ & Ausente \\
\hline & 7 & B & $<3,0$ & $2,3 \times 10^{3}$ & $<1,0 \times 10^{2}$ & Ausente \\
\hline & 8 & $\mathrm{C}$ & 4,0 & $1,0 \times 10^{2}$ & $<1,0 \times 10^{2}$ & Ausente \\
\hline & 9 & $\mathrm{D}$ & 4,0 & $1,3 \times 10^{3}$ & $<1,0 \times 10^{2}$ & Ausente \\
\hline & 10 & E & 9,0 & $3,0 \times 10^{2}$ & $<1,0 \times 10^{2}$ & Ausente \\
\hline & \multicolumn{2}{|c|}{ Padrão Legal*** } & $2,0 \times 10$ & $1,0 \times 10^{3}$ & $1,0 \times 10^{3}$ & Ausente \\
\hline \multirow{6}{*}{ Macarrão na chapa } & 11 & A & $<3,0$ & $<1,0 \times 10^{2}$ & $<1,0 \times 10^{2}$ & Ausente \\
\hline & 12 & B & $<3,0$ & $9,7 \times 10^{3}$ & $<1,0 \times 10^{2}$ & Ausente \\
\hline & 13 & $\mathrm{C}$ & $<3,0$ & $1,6 \times 10^{3}$ & $<1,0 \times 10^{2}$ & Ausente \\
\hline & 14 & $\mathrm{D}$ & $<3,0$ & $<1,0 \times 10^{2}$ & $<1,0 \times 10^{2}$ & Ausente \\
\hline & 15 & E & $<3,0$ & $2,0 \times 10^{2}$ & $<1,0 \times 10^{2}$ & Ausente \\
\hline & \multicolumn{2}{|c|}{ Padrão Legal $* * *$} & $1,0 \times 10^{2}$ & $1,0 \times 10^{3}$ & $1,0 \times 10^{3}$ & Ausente \\
\hline
\end{tabular}

*Número mais provável por grama de alimento. **Unidades formadoras de colônia por grama de alimento. *** RDC n ${ }^{\circ} 12$, de 2 de janeiro de 2001 (Brasil, 2001).

Fonte: Os autores (2021).

\section{Discussão}

Os alimentos mistos, cachorro-quente, hambúrguer e macarrão na chapa apresentam em sua composição, ingredientes pertencentes a vários gêneros alimentícios, de fácil preparação e muito populares nos food trucks, sendo apresentados em composições e preços variáveis (Cunha et al., 2017; Stein et al., 2017).

Em Belo Horizonte o comércio das comidas de rua em food trucks deve atender a legislação vigente, a RDC número 216, que estabelece procedimentos de boas práticas para serviços de alimentação a fim de garantir as condições higiênicosanitárias do alimento preparado (Brasil, 2004). 
O local A se destacou pelas temperaturas adequadas do hambúrguer e macarrão na chapa e os locais B, C, D e E apresentaram temperaturas inadequadas, que podem favorecer ao crescimento de microrganismos patogênicos, a depender do tempo de exposição. No estudo de Monteiro et al. (2017), 78\% das temperaturas do cachorro-quente, hambúrguer e macarrão na chapa comercializados pelos ambulantes de Belo Horizonte estavam também inadequadas, variando entre $24,10{ }^{\circ} \mathrm{C}$ e 87,0 ${ }^{\circ} \mathrm{C}$.

Após serem submetidos à coç̧ão, os alimentos preparados devem ser mantidos em condições de tempo e de temperatura que não favoreçam a multiplicação microbiana. Para conservação a quente, os alimentos devem ser submetidos à temperatura superior a $60^{\circ} \mathrm{C}$ por, no máximo, seis horas (Brasil, 2004). O controle da temperatura durante a conservação da matéria-prima, manipulação, preparação e exposição dos alimentos para o consumo é fator essencial para a garantia da qualidade das refeições servidas, minimizando os riscos de contaminação e crescimento microbiológico (Rocha et al., 2019).

As temperaturas do cachorro-quente variaram de $31,6{ }^{\circ} \mathrm{C}$ a $48,4{ }^{\circ} \mathrm{C}$, sendo que $100 \%$ estavam inadequadas, valor superior ao encontrado por Alves et al. (2015) em Curitiba e São José dos Pinhais (94\%). Para adequar a qualidade higiênicosanitária desse sanduíche recomenda-se manter a salsicha no molho em temperaturas acima de $60{ }^{\circ} \mathrm{C}$ (Brasil, 2004).

Altas contagens de coliformes a $45{ }^{\circ} \mathrm{C}$ foram encontradas em $40 \%$ das amostras de cachorro-quente, assim como no estudo de Ferreti e Alexandrino (2013) e Alves et al (2015). Valores inferiores foram encontrados por Monteiro et al (2017 e Rodrigues et al. (2003), 0\% e 25\% em cachorros-quentes comercializados por ambulantes do estado de Minas Gerais e em Belo Horizonte - MG, respectivamente. Esses microrganismos são indicadores de enteropatógenos, considerados importantes na percepção de condições higiênico-sanitárias inadequadas.

Altas contagens de coliformes a $45^{\circ} \mathrm{C}$ nas amostras de cachorro-quente pode ser justificada por inadequação na higienização e desinfecção de superfícies e na produção; no controle do binômio tempo e temperatura durante a produção e conservação das preparações (Medeiros, Carvalho \& Santos, 2017). A RDC número 12/01 apresenta como um dos indicadores de segurança de carnes cozidas, os coliformes termotolerantes e uma vez contaminado o produto nessa etapa do processo, não existe etapa posterior que possa eliminar a contaminação (Brasil, 2001).

Baldez et al. (2020) identificaram pontos críticos de controle (PCC) no processo produtivo do cachorro-quente comercializado nas ruas em São Luís do Maranhão, dentre eles a cocção da salsicha. Para Lucca e Torres (2002) a cocção da salsicha do cachorro-quente também é um PCC, contudo existem condições benéficas, como o processo de fabricação simples, com poucas etapas e pouco manuseio e consumo imediato ao preparo. Assim, Baldez et al. (2020) sugerem a implantação de BPF para garantir a qualidade do cachorro-quente comercializado nas ruas, concentrando-se na higiene da matéria-prima, equipamentos, instalações, treinamento dos funcionários e, posteriormente, implantação da análise de perigos e pontos críticos de controle (APPCC).

As temperaturas do hambúrguer variaram de $30,6{ }^{\circ} \mathrm{C}$ a $65^{\circ} \mathrm{C}$, sendo superiores às aferidas por Sales, Kuchak $\mathrm{e}$ Caveião, (2016), $30^{\circ} \mathrm{C}$ a $57^{\circ} \mathrm{C}$. Várias etapas ocorrem até que o hambúrguer fique pronto para o consumo, podendo ocorrer riscos de contaminações microbianas. A falta de higiene durante o seu processamento e nos locais onde são preparadas as comidas de rua são os principais fatores de riscos para contaminação cruzada do produto (Pinho et al., 2020).

Os coliformes a $45{ }^{\circ} \mathrm{C}$ estavam dentro dos padrões legais nas amostras de hambúrguer, assim como no estudo de Sales, Kuchak e Caveião (2016); Monteiro et al (2017) e Mahfoozi et al. (2019). Esse resultado satisfatório foi encontrado também no macarrão na chapa. Apesar desses produtos estarem em conformidade com estes padrões microbiológicos, as temperaturas verificadas na coleta apontam um produto inadequado para consumo de acordo com a legislação vigente.

As temperaturas do macarrão na chapa variaram entre $45,1^{\circ} \mathrm{C}$ a $62,3{ }^{\circ} \mathrm{C}$, com $40 \%$ de inadequação, sendo superiores às do cachorro-quente e hambúrguer. Paula et al. (2020) ao avaliarem a temperatura de guarnições, incluindo o macarrão, em restaurantes self-service no centro de Belo Horizonte encontraram também $40 \%$ de inadequação. 
Das amostras coletadas de cachorro-quente, hambúrguer e macarrão na chapa $40 \%$ apresentaram altas contagens de Staphylococcus aureus, indicador de contaminação pós-processo e/ou de sanitização inadequada das superfícies (Rocha, Sousa \& Luz, 2020). No local B foram verificadas altas contagens desse microrganismo em todos os produtos, no local C no cachorro-quente e no macarrão na chapa, e no local D no hambúrguer.

No estudo de Monteiro et al (2017) as contagens de Staphylococcus aureus estavam em conformidade com os padrões legais para o cachorro-quente, hambúrguer e macarrão na chapa. Mahfoozi et al. (2019) detectaram contagens elevadas desse microrganismo em $43 \%$ das amostras de hambúrguer.

O Staphylococcus aureus, comumente encontrado na mucosa nasal de seres humanos é um microrganismo com crescimento em temperaturas que variam de $7^{\circ} \mathrm{C}$ a $47,8^{\circ} \mathrm{C}$, produzindo enterotoxinas termo resistentes a temperaturas entre $10^{\circ} \mathrm{C}$ e $46^{\circ}$, com ótima entre $40^{\circ} \mathrm{C}$ e $45^{\circ} \mathrm{C}$. A intoxicação estafilocócica, no homem, pode causar náusea, vômito, diarreia, dor de cabeça, cólica abdominal, cãibra muscular, queda de pressão sanguínea e prostração (Feitosa et al., 2017). No Brasil, o $S$. aureus é o terceiro patógeno mais comum em surtos de DTA, depois de Salmonella spp. e Escherichia coli (Brasil, 2018).

$\mathrm{O}$ alto índice de DTA desperta para a necessidade de uma maior fiscalização e controle sobre o comércio de alimentos e a melhoria do saneamento básico, bem como a adoção de políticas públicas para difusão da informação sobre higiene à população. A população deve ser informada sobre os riscos de ingerir alimentos de processamento inadequado (Silva et al., 2017).

As contagens de Bacillus cereus nas amostras estavam dentro dos limites preconizados, de modo igual na pesquisa conduzida por Monteiro et al (2017). A bactéria Salmonella spp. não foi detectada em nenhuma amostra, diferindo de Monteiro et al. (2017) que encontrou esse microrganismo no cachorro-quente e hambúrguer.

\section{Conclusão}

Pode-se concluir que a qualidade higiênico-sanitária de 53,3\% das amostras de alimentos - cachorro-quente, hambúrguer e macarrão na chapa comercializados nos food trucks na região central de Belo Horizonte foi insatisfatória devido às altas contagens de coliformes à $45^{\circ} \mathrm{C}$ e Staphylococcus aureus. Em relação às temperaturas, $83 \%$ das amostras estavam em desacordo com a exigência de no mínimo $60^{\circ} \mathrm{C}$.

Como a contagem de coliformes à $45^{\circ} \mathrm{C}$ foi elevada podemos inferir que as condições higiênico-sanitárias do processamento das comidas de rua avaliadas foram inadequadas e provavelmente houve contaminação após a cocção ou inadequação da sanitização das superfícies e higiene pessoal do manipulador, devido às altas contagens de Staphylococcus aureus.

Sugere-se em estudos futuros a avaliação das condições higiênico-sanitárias dos cinco food trucks com a aplicação de check list para diagnosticar as não conformidades, tendo como referência a legislação vigente.

Como as comidas de rua possuem importância econômica e cultural para a população de Belo Horizonte e sua qualidade pode ser afetada por condições ambientais e pela forma como são manipulados, sugere-se que o serviço de vigilância sanitária do município reforce a fiscalização e aplique periodicamente check lists para avaliar a qualidade higiênico-sanitária nos food trucks.

\section{Referências}

Alves, C. C., Périgo, J. S., Sales, W. B., Vasco, J. F. M., Ravazzani, E. D. A., \& Peres, A. P. (2015). Análise microbiológica de cachorro-quente comercializado em vias públicas na cidade de Curitiba e São José dos Pinhais/ PR. Anais do Evento de Iniciação Científica. EVINCI. UniBrasil Centro Universitário, Caderno de Resumos, 1(3). https://portaldeperiodicos.unibrasil.com.br/index.php/anaisevinci/article/view/296/281.

APHA. (2015). Compendium of Methods of Microbiological Examination of Foods. (5th ed.) Salfinger, Y and Tortorello, ML editors, American Public Health Association, Washington DC, 21-23. 
Baldez, A. B. T., Araújo, J. V. F., Lafayete, F. U.M., \& Uchôa, M. R. B. (2020). Análise de Perigos e Pontos Críticos de Controle (APPCC) na produção do cachorro quente comercializado em São Luís/MA. Cadernos UniFOA, 44, 123-132. https://doi.org/10.47385/cadunifoa.v15i44.3286.

Belo Horizonte (2020). Prefeitura Municipal. Rotativo digital. Food trucks poderão ocupar vagas usando apenas um rotativo digital por dia. 11/03/2020. https://prefeitura.pbh.gov.br/noticias/food-trucks-poderao-ocupar-vagas-usando-apenas-um-rotativo-digital-por-dia.

Brasil (2004). Agência Nacional de Vigilância Sanitária. ANVISA. Resolução $n^{\circ}$ 216, de 15 de setembro de 2004. Dispõe sobre Regulamento Técnico de Boas Práticas para Serviços de Alimentação. http://portal.anvisa.gov.br/documents/33916/388704/RESOLU\%25C3\%2587\%25C3\%2583ORDC\%2BN\%2B216\%2BDE\%2B15\%2BDE\%2BSETEMBRO\%2BDE\%2B2004.pdf/23701496-925d-4d4d-99aa-9d479b316c4b.

Brasil (2015). Ministério da Saúde. Agência Nacional Vigilância Sanitária. Resolução número 43, de 1 de setembro de 2015. Dispõe sobre a prestação de serviços de alimentação em eventos de massa. https://www.in.gov.br/materia/-/asset_publisher/Kujrw0TZC2Mb/content/id/32825363/Imprns_Nacional.

Brasil (2018). Ministério da Saúde. Secretaria em Vigilância e Saúde. Surtos de doenças transmitidas por alimentos no Brasil. 2018. http://portalarquivos2.saude.gov.br/images/pdf/2018/julho/02/Apresentacao-Surtos-DTA-Junho-2018.pdf.

Brasil (2019). Ministério da Saúde. Agência Nacional de Vigilância Sanitária. ANVISA. Resolução número 331 de 23 de dezembro de 2019. Dispõe sobre os padrões microbiológicos de alimentos e sua aplicação. Diário Oficial. Brasília, DF. http://www.cvs.saude.sp.gov.br/zip/U_RS-MS-ANVISA-RDC331_231219.pdf.

Costa, A. C. (2017). Food truck: empreendimento no setor de alimentos que está crescendo em Aracaju-SE. Ideias \& Inovação, 4 (1). https://periodicos.set.edu.br/index.php/ideiaseinovacao/article/viewFile/5070/2517.

Cunha, G. C., Lima, A. V. S. C., Leite, T. B., Silva, T. H., Santos, M. R. L., \& Cunha, M.B. (2017). Avaliação da qualidade microbiológica do hambúrguer de carne bovina, de frango e misto. In: Congresso Estadual de Iniciação Científica e Tecnológica do IF Goiano, 4., 2017. Anais do Congresso Estadual de Iniciação Científica e Tecnológica do IF Goiano. Goiânia: IF Goiano, 1-3. https://even3.blob.core.windows.net/anais/58653.pdf.

Feitosa, A. C., Rodrigues, R. M., Torres, E. A. T., \& Silva, J. F. M. (2017). Staphylococcus aureus em alimentos. Revista Desafios, 4(4), 2017. http://dx.doi.org/10.20873/uft.2359-3652.2017v4n4p15.

Ferretti, M. G., \& Alexandrino, A. M. (2013). Avaliação da qualidade higiênico-sanitária de cachorros quentes comercializados em via pública no município de Terra Boa/PR. SaBios: Rev. Saúde e Biol, 8 (3), 83-89. http://www.revista.grupointegrado.br/sabios/.

IBGE (2019). Instituto Brasileiro de Geografia e Estatística. Pesquisa de Orçamento Familiar 2017-2018: primeiros resultados. Coordenação de Trabalho e Rendimento. - Rio de Janeiro: IBGE https://biblioteca.ibge.gov.br/visualizacao/livros/liv101670.pdf

Lemune, A. Q., \& Weber, L. D. (2018). Análise microbiológica de hambúrgueres de carne bovina comercializados em sanduícherias tipo trailer em Cascavel/PR. In: Congresso Nacional de Medicina Veterinária FAG, 2., 2018. Anais do Congresso Nacional de Medicina Veterinária FAG. Cascavel: FAG, 112. http://www.themaetscientia.com/index.php/ACNMVF/article/view/655/676.

Loriato, H. N., \& Pelissari, A. S. (2017). Atributos determinantes na decisão de compra e satisfação dos clientes: um estudo em estabelecimentos que comercializam comida de rua. Revista Brasileira de Pesquisa em Turismo, 11(1). https://rbtur.org.br/rbtur/article/view/1164.

Lucca, A., \& Torres, E. A. F. S. (2002). Condições de higiene de "cachorro-quente" comercializado em vias públicas. Rev Saúde Pública, 36(3):350-352. https://doi.org/10.1590/S0034-89102002000300015.

Mahfoozi, A., Shirzad-Aski, H., Kaboosi, H., \& Ghaemi, E. A. (2019). Identification of the classical enterotoxin genes of Staphylococcus aureus in various foods by multiplex PCR assay. Iranian Journal of Veterinary Research, $20 \quad$ (3), 209-212. https://www.researchgate.net/publication/336869991_Identification_of_the_classical_enterotoxin_genes_of_Staphylococcus_aureus_in_various_foods_by_m ultiplex_PCR_assay.

Medeiros, M. G. G. A., Carvalho, L. R., \& Franco, R. M. (2017). Percepção sobre a higiene dos manipuladores de alimentos e perfil microbiológico em restaurante universitário. Ciência \& Saúde Coletiva, 22(2), 383-392. https://doi.org/10.1590/1413-81232017222.17282015

Mendonça, L. P., Melo, E. C. C., Freire, B. C. F., Barbosa, T. N., Bezerra, A. C. D. S., \& Soares, K. M. P. (2020). Microorganisms, parasites, and nonbiological contaminants in minimally processed fruit salads sold by street vendors. Research, Society and Development, 9(8), e19985234. https://doi.org/10.33448/rsd-v9i8.5234

Monteiro, M. A. M., Dutra, D. B., Torres, F. A., Oliveira, R. B. P., Ribeiro, R. C., \& Garcia, M. A. V. T. (2017). Qualidade microbiológica da comida de rua de Belo Horizonte, Minas Gerais. Demetra, 12(3), 781-794. http://dx.doi.org/10.12957/demetra.2017.27519.

Paula, L. A. S., Amorim, M. M. A., Lima, A. C. J., Silva, F. E. C., Gomes, L. H. A. L., Ribeiro, M. A., Miranda, M. R. R., Coelho, M. M., \& Amaral, D. A. (2020). Análise de boas práticas de fabricação em restaurante self service no centro de Belo Horizonte, Brasil. Revista 100-Cs, 6(2). http://revistainclusiones.com/carga/wp-content/uploads/2021/03/5-V6-JULIODICIEMBRE100CS2020-100CSREV.pdf.

Pereira, A, S., Shitsuka, D. M., Parreira, F. J., \& Shitsuka, R. (2018). Metodologia da pesquisa científica. UFSM, NTE, 2018.1 e-book. https://repositorio.ufsm.br/bitstream/handle/1/15824/Lic_Computacao_Metodologia-Pesquisa-Cientifica.pdf?sequence=1.

Pertile, K. (2013) Comida de Rua: Relações Históricas e Conceituais. Revista Rosa dos Ventos 5(2) 301-310, 2013. http://www.unirio.br/cch/escoladeturismologia/pasta-virtuais-de-docentes/joice-lavandoski/alimentos-e-bebidas/textos-deapoio/Comida\%20de\%20rua.\%20.pdf.

Pinho, J. P. A., Sousa, J. V., Bezerra, K. C. B., \& Carvalho, L. M. F. (2020). Qualidade microbiológica de sanduíches tipo hambúrguer: uma revisão. Research, Society and Development, 9(10), e10009109479, 2020. http://dx.doi.org/10.33448/rsd-v9i10.9479. 
Research, Society and Development, v. 10, n. 12, e227101220376, 2021

(CC BY 4.0) | ISSN 2525-3409 | DOI: http://dx.doi.org/10.33448/rsd-v10i12.20376

Rocha, L. A., Rodrigues, L. M., Araújo, M. C., Soares, T. C., Barbosa Gomes, S. A., \& de Oliveira, E. S. (2019). Analysis of the temperature control of foods served in a University Food and Nutrition Unit in the city of Picos, state of Piauí, Brazil. Research, Society and Development, 8(2), e882563. https://doi.org/10.33448/rsd-v8i2.563.

Rocha, R. E., Sousa, R. S., \& Luz, L. E. (2020). Research of Staphylococcus aureus in Nile Tilapia (Oreochromis niloticus) commercialized in the semi-arid region of Piauí. Research, Society and Development, 9(7), e222974034. https://doi.org/10.33448/rsd-v9i7.4034

Rodrigues, K. L., Gomes, J. P., Conceição, R. C. S., Brod, C. S., Carvalhal, J. B., \& Aleixo, J. A. G. (2003) Condições higiênico-sanitárias no comércio ambulante de alimentos em Pelotas-RS. Ciência Tecnológica de Alimentos, 23 (3), 447 452. https://doi.org/10.1590/S0101-20612003000300026

Sales, W. B., Kuchak, K. C., \& Caveirão, C. (2016). Determinação de coliformes totais e termotolerantes em hambúrgueres vendidos em fast foods na cidade de Curitiba/Paraná. Revista da Universidade Vale do Rio Verde, 14 (2), 412-420. http://dx.doi.org/10.5892/ruvrd.v14i2.2698.

Silva, J. C. G., Filho, M. M. S., Nascimento, G. V., Pereira, D. A. B., \& Junior, C. E. O. C. (2017). Incidência de doenças transmitidas por alimentos (DTA) no estado de Pernambuco, um acompanhamento dos dados epidemiológicos nos últimos anos. Ciência Biológica e de Saúde Unit, 3(1). https://periodicos.set.edu.br/index.php/facipesaude/article/view/4180.

Stein, G., Zarth, N., Oliveira, E. C., \& Adami, F. S. (2017). Análise microbiológica de cachorros-quentes comercializados por food trucks. Revista Caderno Pedagógico, 14(1), 193-202. http://dx.doi.org/10.22410/issn.1983-0882.v14i1a2017.1440 